\title{
PERCEPÇÃO AMBIENTAL E DINÂMICA GEOECOLÓGICA: PREMISSAS PARA O PLANEJAMENTO E GESTÃO AMBIENTAL
}

\author{
Environmental perception and geoecological dynamics: \\ Premises for planning and environmental management
}

\author{
Eder Mileno Silva De Paula \\ Universidade Federal do Pará, Altamira, Pará, Brasil \\ edermileno@ufpa.br \\ Edson Vicente da Silva \\ Universidade Federal do Ceará, Fortaleza, Ceará, Brasil \\ cacauufc@gmail.com \\ Adryane Gorayeb \\ Universidade Federal do Ceará, Fortaleza, Ceará, Brasil \\ adryanegorayeb@yahoo.com.br
}

Artigo recebido em 10/04/2014 e aceito para publicação em 31/07/2014

RESUMO: É necessário planejar as ações do ser humano na natureza, organizar intervenções sustentáveis dentro dos limites ambientais, e gerir os recursos naturais através de comparações com outras paisagens já modificadas. Entretanto, grande parte das ações de planejamento e gestão ambiental se dão através de análises setoriais, sem entender como a população local percebe os seus lugares de vivência. Nesse artigo, discute-se sobre a análise geoecológica da paisagem e suas relações com o pensamento complexo, e sobre a importância da educação ambiental como forma de difusão do conhecimento geoecológico da paisagem. Propõe-se elementos entendidos como fundamentais para o planejamento e gestão ambiental dos recursos naturais e das paisagens, através de considerações acerca da necessidade de conhecimentos sobre a percepção ambiental dos atores sociais, de suas ações no ambiente natural, e das repercussões dessas ações na dinâmica geoecológica local. O uso da terra contribui significativamente para mudanças na dinâmica ambiental local, e assim, o entendimento sobre a dinâmica geoecológica e a percepção ambiental das comunidades locais devem ser encarados como premissas para elaboração das estratégias de planejamentos e gestão ambiental.

Palavras-chave: Paisagem; Planejamento Ambiental; Embaubal; Belo Monte.

ABSTRACT: It is necessary to plan the actions of humans in nature, organizing sustainable interventions within environmental limits, and manage natural resources through comparisons with other landscapes already changed. But, part of the actions of environmental planning and management occur through sectoral analyzes, and without understanding how the local population perceives the nature. In this article we discuss about the geoecological landscape analysis and its relationship with the complex thinking and the importance of environmental education as a means of dissemination of geoecological knowledge of the landscape. It proposes fundamental elements for environmental planning and management of natural resources, through considerations about the need for knowledge of the environmental perception of social actors on their actions on the natural environment, and the impact of these actions on the local geoecological dynamics. The land use contribute significantly to 
changes in local environmental dynamics. Thus, the understanding of the geoecological dynamics, such as environmental perception of local communities, should be seen as premises for development of environmental planning and management.

Key-words: Landscapes; Environmental Planning; Embaubal; Belo Monte.

\section{INTRODUÇÃO}

A sociedade - e suas relações com a natureza - está em constate evolução: mudam os costumes das pessoas, as suas formas de pensar sobre as coisas e sobre o mundo; altera-se o mundo, que se modela de acordo com as necessidades presentes, ou por conjecturas de necessidade; novas relações entre os componentes, e entre as paisagens são estabelecidas; novas paisagens surgem, entretanto algumas desaparecem. As paisagens se adaptam constantemente, sendo que o novo pode não ter sido necessariamente o que foi almejado pelas ações humanas.

No contexto atual, é essencial o exercício de planejar as ações da sociedade na natureza, de organizar intervenções sustentáveis dentro dos limites ambientais, e de gerir os recursos naturais através de comparações com outras paisagens já modificadas.

Neste artigo, constrói-se algumas reflexões sobre a análise geoecológica da paisagem e suas relações com o pensamento complexo; sobre a educação ambiental como forma de difusão do conhecimento geoecológico da paisagem, propondo-se elementos entendidos como fundamentais para o planejamento do uso conservacionista e da preservação dos recursos naturais. Acrescenta-se considerações sobre as repercussões das ações sociais na dinâmica geoecológica local, além da necessidade de entendimento da percepção ambiental dos atores sociais sobre suas ações no ambiente natural.

O território escolhido para realizar proposições e considerações quanto à sustentabilidade ambiental, ou seja, o sujeito/objeto dessa pesquisa, é o Arquipélago do Embaubal, localizado na foz do Rio Xingu, na Amazônia Oriental. Constitui um ambiente de elevada diversidade biológica e beleza cênica surpreendentes, e suas ilhas são construídas com a deposição de sedimentos transportados pela dinâmica ambiental do Rio Xingu. Algumas ilhas possuem formações arbóreas de várzea, com presença de solos consolidados, enquanto outras são constituídas em grande parte por sedimentos inconsolidados, com a existência de plantas herbáceas e arbustivas como cobertura vegetal. Observa-se que o mesmo fluxo hídrico fluvial que trouxe sedimentos para formar as ilhas, pode também as destruir, através de processos erosivos que se intensificam a partir da degradação ambiental ocasionada pelo uso inadequado dos recursos naturais nas planícies fluviais da área em questão.

As principais fontes de alteração paisagística são constituídas por atividades promovidas pelos habitantes de Senador José Porfírio e Vitória do Xingu, sendo que as águas no entorno das ilhas servem de rotas fluviais interligando esses municípios, a partir do Porto de Vitória do Xingu a outras localidades no Estado do Pará. Acrescenta-se que o aproveitamento hidroelétrico do Rio Xingu e a possível mineração de ouro, à montante do Arquipélago, deverão comprometer significativamente o transporte de sedimentos que contribuem para a formação das ilhas, como a composição química da água, e consequentemente, irão alterar a sua dinâmica geoecológica local.

Como objetivos desse trabalho científico almeja-se apoiar ações conservacionistas que possibilitem a sustentabilidade ambiental do Arquipélago do Embaubal, e, consequentemente, preservar o principal banco reprodutor da tartaruga-da-amazônia (Podocnemis expansa) na América do Sul.

\section{PERCURSO METODOLÓGICO}

A pesquisa possui como aporte teórico-metodológico a Geoecologia das Paisagem, método difundido por Sotchava (1978), Rodriguez (1998) e Rodriguez, Silva e Cavalcanti (2013), que apresenta um enfoque complexo, sistêmico e interdisciplinar.

O primeiro momento do percurso metodológico dessa pesquisa refere-se a uma sistemática revisão bibliográfica sobre Geoecologia da Paisagem, Educação Ambiental e Percepção Ambiental, para fomentar a análise teórico-conceitual da pesquisa.

Em um segundo momento, coletou-se informações referentes a documentos cartográficos, tais 
como mapas temáticos e imagens de satélite, assim como outros documentos bibliográficos que, junto às verificações em campo, subsidiaram as considerações sobre a dinâmica geoecológica da paisagem e o mapeamento na escala de 1:200.000 do uso da terra, da cobertura vegetal e das unidades geoecológicas do Arquipélago do Embaubal.

\section{ENTENDIMENTOS CONCEITUAIS}

\section{Análise Geoecológica da Paisagem e Teoria da Complexidade}

Cientistas que fundamentam a teoria e metodologia de suas pesquisas na Geoecologia da Paisagem, de acordo com Rodriguez, Silva e Cavalcanti (2013), buscam um sistema único de caracterização, análise e mapeamento das paisagens; o desenvolvimento conceitual e de procedimentos normativos na avaliação paisagística; além da aplicação de métodos adequados à elaboração de pesquisas ambientais.

Rodriguez (1998) apud Rodriguez, Silva e Cavalcanti (2013, p. 40) indica que o esquema metodológico para a Análise Geoecológica da Paisagem perpassa pelo estudo da organização do sistema; classificação, função e taxionomia das estruturas; e conhecimento dos fatores modificadores das paisagens. Em dado momento, deve-se avaliar "o potencial das paisagens e tipologias funcionais [...] e dos impactos geoecológicos das atividades humanas, das funções e cargas econômicas".

A conclusão das pesquisas geoecológicas propõe o planejamento e a gestão ambiental das paisagens, visando o desenvolvimento sustentável, a organização estrutural-funcional, direcionados à otimização dos recursos e à sua perícia e monitoramento (RODRIGUEZ, 1998, apud RODRIGUES; SILVA; CAVALCANTI, 2013).

Nos estudos geoecológicos, a paisagem é considerada como parte da superfície terrestre, na qual os componentes individuais da natureza se encontram em estreita relação uns com os outros, e como um todo interatuam com as partes vizinhas da esfera natural e da sociedade.

A Geoecologia da Paisagem tem seus princípios baseados na Teoria Geral dos Sistemas proposta por Bertalanfy (1968), por isso não está somente preocupada em compreender as partes da paisagem - do sistema -, está interessada em compreender a amplitude, em buscar o entendimento do todo. A Teoria Geral dos Sistemas, por sua vez, assume como objeto de estudo estabelecer relações entre os vários sistemas que compõem o mundo, assim como entre os elementos que compõem o sistema, verificando hierarquias e "seus modos de ação ou comportamento" (MACIEL, 1974, p. 21).

Para Camargo (2005, p. 51), a Teoria Geral dos Sistemas e a Teoria da Complexidade "se integram por apresentarem formas próximas de perceber o mundo", fato que coloca a Geoecologia da Paisagem contextualizada na revolução do pensamento contemporâneo sobre o mundo, indicada por Morin (2010) como necessária para responder as perguntas contemporâneas, por buscar entender o todo, e não apenas uma das partes do sistema, evitando especializações que não percebem relações contextuais e globais. A Teoria da Complexidade constitui uma forma de pensamento que se esforça para unir, contextualizar e globalizar, percebendo a realidade em estruturas e evoluindo em um conjunto de inter-relações e retroalimentações, em um processo de auto-organização (LEFF, 2003; MORIN, 2010).

Para Morin (2010, p. 28), o sistema "é mais que a soma das partes, isto é, no nível do todo organizado há emergências e qualidades que não existem no nível das partes quando são isoladas. Tais emergências podem retroagir sobre as partes", sendo que a não percepção das retroações do sistema, segundo o autor, podem levá-lo à "explosão ou transformação, à revolução" em um outro sistema, no qual seus elementos podem seguir caminhos evolutivos diferenciados do sistema anterior, ou mesmo serem extintos.

O entendimento do fluxo fluvial, sua relação com a inundação sazonal dos solos, a influência no tipo de cobertura vegetal e a dependência dos usos dos recursos naturais constituem partes do todo que devem ser analisadas de forma integrada, percebendo suas inter-relações, para que se possa contribuir com a continuidade do geossistema atual. O entendimento complexo do ambiente verificado nos estudos que utilizam como método a Geoecologia da Paisagem, contribui com respostas complexas às perguntas com- 
plexas do mundo contemporâneo, com o entendimento do todo, afastando-se das análises setoriais, e com objetivo claro de planejamento e gestão da paisagem de forma integrada e interdisciplinar.

\section{Educação ambiental aplicada à difusão do conheci- mento Geoecológico da Paisagem}

Entender a Geoecologia das Paisagens remete à utilização de um conjunto de procedimentos metodológicos com o objetivo de diagnosticar a paisagem de forma integrada e holística, sendo que essas informações devem, de acordo com Silva e Rodriguez (2011, p 2), "subsidiar programas de desenvolvimento socioeconômico, e planos de gestão e manejo territorial".

Os planejamentos e a gestão ambiental necessitam ser participativos, onde os diferentes grupos da sociedade se envolvem para o planejamento das ações na paisagem. Para Silva (2012), a educação ambiental emerge como instrumento de efetivação dos planos de gestão participativa.

A educação ambiental que se almeja nesse contexto de planejamento e gestão participativa deve entender e ensinar às pessoas sobre o mundo através de suas complexidades, através de um pensamento holístico e reintegrador das partes fragmentadas do conhecimento. Segundo Leff (2003), a ruptura do conhecimento fragmentado do mundo está relacionada com os paradigmas interdisciplinares e as transdisciplinares do conhecimento.

O Instituto Brasileiro Sócio-Ambiental IBASA (2004) acrescenta que somente métodos de ensino-aprendizagem que vislumbrem uma educação emancipatória, buscando explicitação de conflitos e estratégias coletivas, constituem condição para uma gestão socioambiental eficiente e democrática.

É necessário estabelecer uma Educação Ambiental por meio de uma visão integrada para o planejamento e gestão sustentável. Rodriguez e Silva (2013) sugerem que essa visão deve ser:

- Democrática e participativa, envolvendo todos os setores sociais, econômicos, políticos e culturais;

- Ajustada ao estilo de desenvolvimento que se permite construir, atrelado à conservação ambiental e à melhoria da qualidade de vida;

- Integrada aos comportamentos científicos, éticos e compromissos sociais;

- Articulada ao conhecimento científico, ao saber popular e à preocupação ambiental;

- Baseada nas diferentes características dos sistemas ambientais, suas limitações e potencialidades;

- Concebida através de uma nova concepção de percepção, paradigma e mentalidade ambientais;

- Vinculada a um maior grau de organização social e incorporação de sustentabilidade socioambiental;

- Aproveitada na construção de um desenvolvimento sustentável, com novas tecnologias ao saber autóctone. (SILVA; RODRIGUEZ e VALDÉZ, 2012 p. 111-112).

Silva (2012) e Milbrath (1996) afirmam o pensamento ambiental com posturas e visões que envolvam concepções holísticas, sistêmicas, integrativas-complexas e dinâmicas, e que pode:

adquirir uma visão mais ampla e abrangente na interpretação do contexto atual das relações sociedade e natureza, onde se concebe uma multidimensionalidade e multireferencialidade, e uma maior integração entre a inter e a transdisciplinaridade (SILVA, 2012, p. 178; MILBRATH, 1996).

$\operatorname{IBASA}(2006$, p. 11) destaca a importância de se iniciar o processo de gestão a partir do entendimento que educadores e educandos "possuem sobre educação e meio ambiente para, então, entender a educação ambiental em sua diversidade, com as suas consequências práticas". Deixando clara a necessidade de estudos sobre a percepção ambiental dos envolvidos, para a construção adequada das metodologias pedagógicas que permitem a construção de uma nova percepção do ambiente.

Entende-se que o entendimento atual da percepção ambiental e o conhecimento da dinâmica geoecológica da paisagem são essenciais para o planejamento e a gestão ambiental, constituindo-se 
critérios norteadores das intervenções educativas junto às populações locais e de seu entorno.

\section{DISCUSSÕES E PROPOSIÇÕES}

\section{Percepção Ambiental: premissa no Planejamento e Gestão Ambiental}

As ações de planejamento e de gestão ambiental de qualquer paisagem devem considerar um conhecimento prévio sobre as relações existentes entre a sociedade e a natureza, que viabilizam resoluções de conflitos ambientais e, consequentemente, a gestão alcança resultados benéficos. Nesse sentido, Leff (2003, p.59), sobre a busca em entender a complexidade ambiental, indica a necessidade de "um reconhecimento do mundo com base nas leis-limite da natureza [...] e da cultura $[\ldots] "$.

O estudo da percepção ambiental é fundamental para que se possa compreender as relações entre o meio social e a natureza; expectativas, satisfações e insatisfações, julgamentos e condutas da sociedade. Cada indivíduo percebe, reage e responde diferentemente, sendo suas respostas ou manifestações resultantes das percepções, dos processos cognitivos, julgamentos e expectativas de cada um. (FERNANDES, 2008; PALMA, 2005 apud TORRES e OLIVEIRA, 2008).

A realização de estudos de percepção ambiental possibilita por parte dos planejadores e gestores o conhecimento das expectativas da população envolvida, de suas necessidades, propiciando acordos de conduta em consonância com as limitações e potencialidades geoecológicas da paisagem. Como ressalta os estudos do IBASA (2006) em relação às Unidades de Conservação - UC e suas áreas de entorno, a gestão ambiental depende da compreensão que as pessoas têm do ambiente.

É crescente o interesse em envolver, principalmente as comunidades locais, nos esforços conservacionistas, pois a cada momento torna-se mais lúcido o fato de que somente com o envolvimento das comunidades, os objetivos conservacionistas serão alcançados.

As comunidades que vivem ou usufruem dos recursos do Arquipélago do Embaubal vivenciam a expectativa da instituição de criar Unidades de Conservação-UC pelo Governo do Estado do Pará, sendo uma UC de uso sustentável e outra de proteção integral. A escolha dos tipos de UC, como de seus limites, foi estabelecida em parte pelos gestores, e a outra parte em reuniões com a comunidade, principalmente com os representantes dos pescadores e pesquisadores. $\mathrm{Na}$ reunião os gestores apresentaram uma proposta de limites para as UC, e os pescadores solicitaram mudanças de acordo com suas necessidades de pesca.

Não existem estudos voltados para o entendimento da comunidade sobre a importância de conservação do Arquipélago, e ainda não há uma devida compreensão sobre a dinâmica geoecológica dessas paisagens. Conhecimento que entende-se como basilar para o planejamento e gestão ambiental participativa.

Os gestores, pesquisadores e a comunidade precisam conhecer as limitações, potencialidades e problemas geoecológicos do Arquipélago, para indicar quais são as áreas que devem ou não participar dos limites de uma UC. Acredita-se que somente com esse entendimento, os planejamentos e suas execuções possam vir a serem eficientes.

\section{Considerações sobre ações sociais na dinâmica geo- ecológica do Arquipélago do Embaubal}

O Arquipélago do Embaubal possui uma dinâmica ambiental singular, uma vez que está localizado na foz do Rio Xingu, tem o seu nível de água controlado diariamente pela dinâmica das marés do Rio Amazonas, e sazonalmente, nos seus períodos de vazante fluvial, entre os meses de junho e novembro, e de cheia durante o resto do ano.

O uso e ocupação das terras e das águas de entorno das ilhas do Embaubal iniciou-se no século XVII, impulsionado por missões jesuíticas que desbravaram a região, hoje reconhecida como Transamazônica e Xingu. Os principais usos naquele século foram o extrativismo de látex das seringueiras e a pesca de Tartarugas-da-Amazônia (Podocnemis expansa) para produção de óleo. O Arquipélago recebe o nome de Embaubal por causa da sua praia mais famosa, praia do Embaubal, que se constitui como a praia insular sazonal que abrigou a desova das Tartarugas-da-Amazônia.

Dois usos principais contribuem para mu- 
danças morfométricas das ilhas, praias e canais, e, inevitavelmente, provocam mudanças na dinâmica geoecológica do Arquipélago, a saber: transporte de passageiros e cargas por embarcações; e a mineração de areia para construção civil (Figura 1). O sistema de transporte fluvial de passageiros e cargas utiliza-se de embarcações de pequeno e médio porte. Essas embarcações ligam o principal porto da região, localizado em Vitória do Xingu, às cidades de Senador José Porfírio, Santarém e Belém. O fluxo dessas embarcações próximas às ilhas produzem ondas que erodem as praias fluviais, provocando tombamentos de árvores e assoreamento dos canais.

A mineração de areia para a construção civil, explorada no Rio Xingu, consiste na retirada de sedimentos de granulometria diversa do leito dos canais no entorno das ilhas, que acabam provocando escorregamentos de sedimentos das margens das ilhas, trazendo consequências semelhantes às atividades de transporte de passageiros e cargas. $\mathrm{O}$ assoreamento dos canais que separam as ilhas comprometem tanto a biota local, quanto o transporte de cargas e passageiros. Nos períodos de vazante, com a diminuição do nível de base local, alguns canais tornam-se inavegáveis, mudando as rotas das embarcações, que, por vezes, causam acidentes, envolvendo atropelamentos de espécimes da fauna.

Figura 01: Unidades Geoecológicas do Arquipélago do Embaubal, localizado no Rio Xingu - Amazônia Oriental.

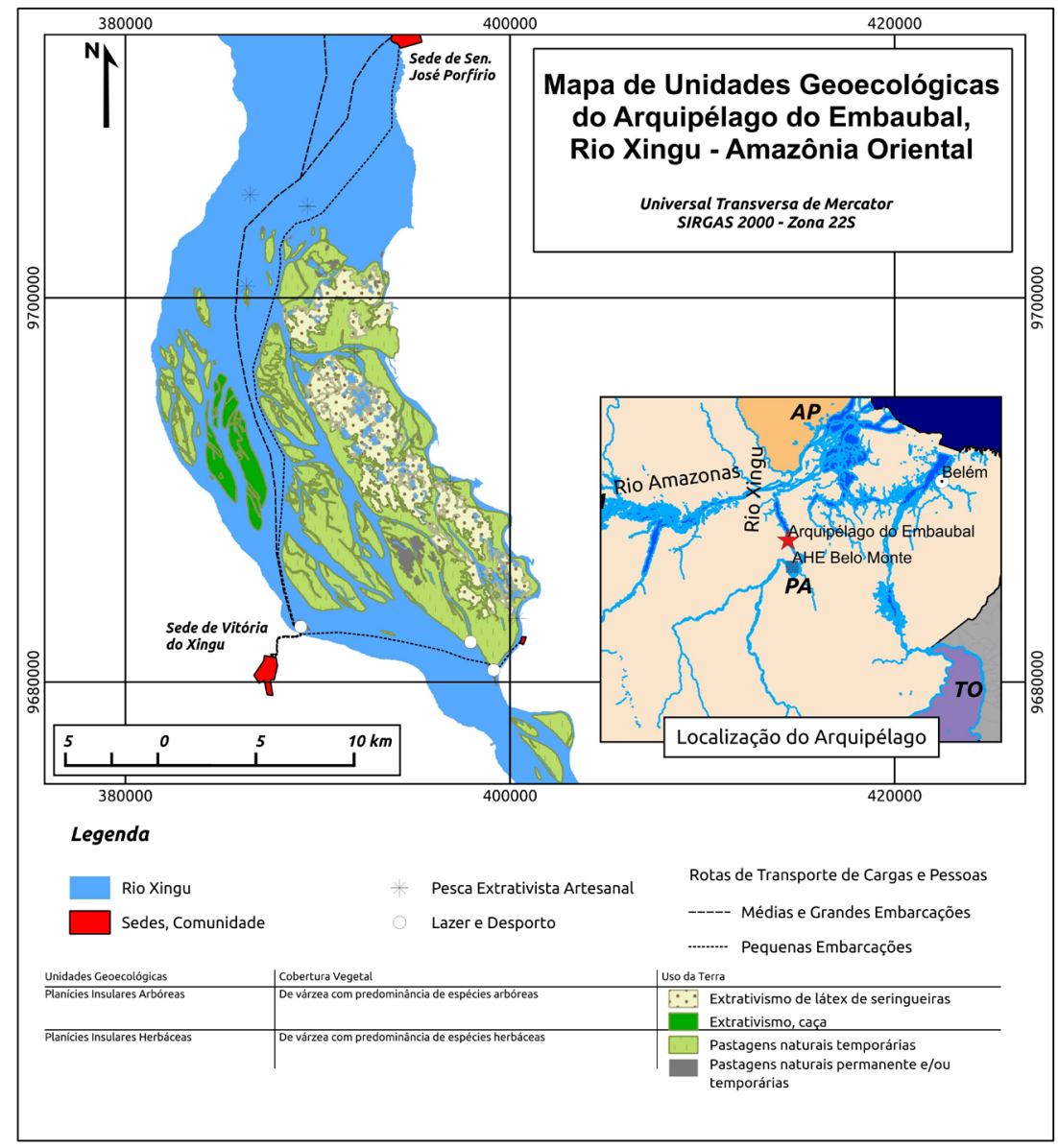

Elaboração dos autores. 
A maior ilha do Arquipélago, a Ilha Grande (Figura 01), sofreu no início da década de 1980 um grande incêndio, que destruiu parte de sua formação arbórea, de acordo com relatos de populares. A área iniciou seu processo de recuperação vegetacional com herbáceas, que no momento são utilizadas como pastagens permanentes pela pecuária local.

A pastagem natural nas áreas de várzea herbácea no Arquipélago é utilizada de forma permanente e/ou temporária, sendo destinada ao pastoreio de rebanhos bovinos e bubalinos. Essa forma de exploração retarda a pedogênese e, consequentemente, a fixação e desenvolvimento de espécies arbóreas.

Os usos da terra na bacia do Rio Xingu contribuem significativamente para mudanças na dinâmica ambiental do Arquipélago do Embaubal. As áreas de desflorestamento identificadas pelo Projeto de Monitoramento da Floresta Amazônica Brasileira por Satélite - PRODES, cuja bacia integra, tem seus solos lixiviados e erodidos, que além de provocarem assoreamento dos afluentes, leva uma carga extra de sedimentos para o curso principal do Rio Xingu.

Do ponto de vista da necessidade de que haja sedimentos para formação ou manutenção das ilhas, a carga extra destes recebida pelo Rio Xingu ainda que benéfica, pode, entretanto, causar mudanças repentinas no habitat aquático e resultar em perdas irremediáveis para a fauna local.

Uma outra grande mudança na bacia do Rio Xingu é anunciada com a construção dos barramentos, canais, diques, reservatórios, dentre outras obras artificiais para o Aproveitamento Hidroelétrico-AHE de Belo Monte. Com as obras iniciadas em 2011, e com prazo de implantação total de 10 anos, o AHE Belo Monte terá capacidade de 11.233,1 MW de acordo com Leme Engenharia (2009). O mesmo autor indica que a operação da AHE Belo Monte será realizada a fio d'água, e a energia produzida será distribuída para as regiões Norte, Nordeste e Sudeste do Brasil, pois fará parte do Sistema Interligado Nacional - SIN.

A construção de imóveis para atender às demandas provocadas pela AHE Belo Monte, intensificou a mineração de sedimentos de granulometrias diversas no leito do Rio Xingu, principalmente em Altamira, além do aumento de áreas desflorestadas e do fluxo de grandes embarcações com insumos para obras.

E, a exemplo de outras obras com barramento do fluxo fluvial natural, o Rio Xingu após a construção de AHE Belo Monte, terá um novo regime sedimentológico, embora ainda não existindo estudos pormenorizados sobre o tema. Entretanto, persiste o entendimento de que há uma necessidade da chegada de sedimentos até a foz do Rio Xingu para formação de novas ilhas, e para a manutenção das existentes, e que este regime sedimentar será comprometido.

Os barramentos dos sedimentos pela hidrelétrica de Belo Monte, e consequentemente, a redução da ocorrência de sedimentos ao longo do escoamento à jusante da AHE, provocará um aumento da energia do escoamento disponível para os processos erosivos na calha do Rio, com possíveis modificações das áreas deposicionais do Rio Xingu à jusante da obra.

\section{CONSIDERAÇÕES FINAIS}

Está claro que somente o entendimento da paisagem de forma sistêmica e holística poderão solucionar os problemas complexos impostos pela sociedade humana. A Geoecologia da Paisagem está contextualizada na revolução do pensamento contemporâneo por buscar entender o todo, e não apenas uma das partes do sistema, evitando especializações que não percebem as relações contextuais e globais.

A Geoecologia da Paisagem é um caminho metodológico capaz de apontar soluções adequadas aos limites e potencialidades dos ambientes naturais e sociais. Assim, a Educação Ambiental assume papel de mediadora na construção de um novo pensamento integrador sobre o mundo, com fins de planejamento e gestão ambiental.

A educação ambiental deve entender e ensinar às pessoas sobre o mundo através de suas complexidades, através de um pensamento holístico e reintegrador das partes fragmentadas do conhecimento.

Os processos de planejamento ambiental devem desde o início ser participativos, e é preciso ouvir com zelo a experiência das comunidades científicas e tradicionais, assim como devem ser realizadas intervenções sensibilizadoras sobre as limitações e potencialidades do uso da paisagem.

A realização de estudos de percepção ambiental possibilita por parte dos planejadores e gestores o conhecimento das expectativas da população envolvida, de suas necessidades, propiciando acordos de conduta em consonância com as limitações e potencialidades geoecológicas da paisagem.

$\mathrm{O}$ uso da terra na bacia do Rio Xingu e no trecho que contém o Arquipélago contribuem significativamente para mudanças na dinâmica ambiental 
local. Assim, o entendimento da dinâmica geoecológica do Arquipélago Embaubal, assim como a percepção ambiental das comunidades envolvidas devem ser encarados como premissas para elaboração dos planejamentos, sendo o caminho mais adequado para gestão participativa.

\section{REFERÊNCIAS}

CAMARGO, L. H. R. de. A ruptura do meio ambiente: Conhecendo as mudanças ambientais do planeta através de uma nova percepção da ciência: a geografia da complexidade. Rio de Janeiro: Bertrand Brasil, 2005. $240 \mathrm{p}$.

DE PAULA, E. M. S.; DE PAULA, J. M. O. DE.; OLIVEIRA, I. R. A.; SILVA, P. R. P. da. Considerações sobre as repercussões dos usos da terra na dinâmica ambiental do Arquipélago do Embaubal - Rio Xingu - Pará. In: SIMPÓSIO DE GEOGRAFIA FÍSICA APLICADA, 15., 2013, Vitória. Anais... Vitória:UFES, 2013.

IBASA - INSTITUTO BRASILEIRO DE ANÁLISES SOCIAIS E ECONÔMICAS (Brasil). Educação ambiental e gestão participativa em unidades de conservação. Rio de Janeiro: IBASA, 2003.30 p. Disponível em: <www.ibase.br>. Acesso em: 30 out. 2013.

IBASA - INSTITUTO BRASILEIRO DEANÁLISES SOCIAIS E ECONÔMICAS (Brasil). Educação ambiental em unidades de conservação. Rio de Janeiro: IBASA, 2006. 30 p. Disponível em: <www.ibase.br>. Acesso em: 30 out. 2013.

LEFF, E. Pensar a complexidade ambiental. In: LEFF, E. A complexidade ambiental. São Paulo: Cortez, 2003. p. 15-64.

LEME ENGENHARIA. Aproveitamento hidroelétrico de Belo Monte: Relatório de Impacto Ambiental - Rima. Leme Engenharia, 2009. 197 p. Disponível em: <www.eletrobras.com>. Acesso em: 14 fev. 2014.

MILBRATH, L. W. Learning to think environmentally while the is still fime. Albany: State University of New York, Press, 1996.

MORIN, Edgar. Por uma reforma do pensamento. In: PENA-VEGA, A.; ALMEIDA, E. P. (Org.). O pensar complexo: Edgar Morin e a crise da modernidade. Rio de Janeiro: Garamond, 2010.

RODRIGUES, A. M. A abordagem ambiental unifica as geografias? In: MEDONÇA, F.; LOWEN-SAHR, C. L.; e SILVA, M. da (Org.). Espaço e Tempo: Complexidade e desafios do pensar e do fazer geográfico. Curitiba: Associação de Defesa do Meio Ambiente e Desenvolvimento de Antonina (ADEMADAN), 2009. p.167-180

RODRIGUEZ, J. M. M. La ciencia del paisaje a la luz del paradigma ambiental. Cadernos de Geografia. Belo Horizonte, v. 8, n. 10, 1998. p. 63-68.

RODRIGUEZ, J. M. M.; SILVA, E. V. Educação Ambiental e Desenvolvimento Sustentável: problemas, tendências e desafios. Fortaleza: Edições UFC, 2013.

RODRIGUEZ, J. M. M.; SILVA, E. V.; CAVALCANTI, A. P. B.. Geoecologia das Paisagens: Uma visão geossistêmica da análise ambiental. Fortaleza: Edições UFC, 2013, 222p., il..

SILVA. E. V. da. Geografia Física, Geoecologia da Paisagem e Educação Ambiental Aplicada: Interações Interdisciplinares na Gestão Territorial. Revista Geonorte. v.4, n.4, p.175-183, 2012.

SILVA. E. V. da; RODRIGUEZ, J. M. M. Geoecologia da Paisagem: Zoneamento e Gestão Ambiental em Ambientes Úmidos e Subúmidos. Revista Geográfica de América Central. Número Especial EGAL, 2011, p. 1-12.

SILVA. E. V. da; RODRIGUEZ, J. M. M.; VALDÉZ, A. C. Educação Ambiental Aplicada: Aportes Metodológicos da Biogeografia e da Geoecologia das Paisagens na Gestão Territorial. Revista Geonorte. v.3, n.4, p. 106-113, 2012.

SOCTCHAVA, V. B. Por uma teoria de classificação de geossistemas de vida terrestre. Biogeografia. São Paulo, 1978. 13p.

TORRES, D. F; OLIVEIRA E. S. Percepção Ambiental: Instrumento para Educação Ambiental em Unidades de Conservação. Rev. Eletrônica Mestr. Educ. Ambiental. V. 21, p.1517-1256, 2008. 